\title{
A bright cadmium-free, hybrid organic/quantum dot white light-emitting diode
}

Xuyong Yang, Yoga Divayana, Dewei Zhao, Kheng Swee Leck, Fen Lu, Swee Tiam Tan, Agus Putu Abiyasa, Yongbiao Zhao, Hilmi Volkan Demir, and Xiao Wei Sun

Citation: Appl. Phys. Lett. 101, 233110 (2012);

View online: https://doi.org/10.1063/1.4769347

View Table of Contents: http://aip.scitation.org/toc/apl/101/23

Published by the American Institute of Physics

\section{Articles you may be interested in}

High color purity ZnSe/ZnS core/shell quantum dot based blue light emitting diodes with an inverted device structure

Applied Physics Letters 103, 053106 (2013); 10.1063/1.4817086

Solution processed multilayer cadmium-free blue/violet emitting quantum dots light emitting diodes Applied Physics Letters 101, 053303 (2012); 10.1063/1.4738375

White-blue electroluminescence from a Si quantum dot hybrid light-emitting diode Applied Physics Letters 106, 201102 (2015); 10.1063/1.4921415

High color rendering index white light emitting diodes fabricated from a combination of carbon dots and zinc copper indium sulfide quantum dots

Applied Physics Letters 104, 261106 (2014); 10.1063/1.4886415

Fabrication of white light-emitting diodes based on solvothermally synthesized copper indium sulfide quantum dots as color converters

Applied Physics Letters 100, 183104 (2012); 10.1063/1.4711019

Electron-electron and electron-hole interactions in small semiconductor crystallites: The size dependence of the lowest excited electronic state

The Journal of Chemical Physics 80, 4403 (1998); 10.1063/1.447218

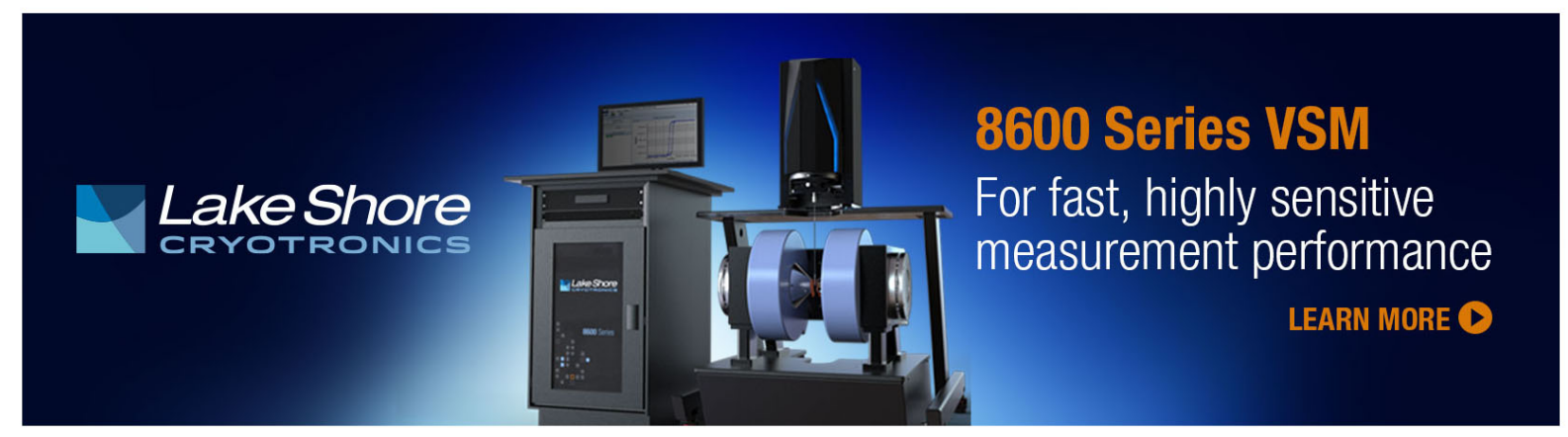




\title{
A bright cadmium-free, hybrid organic/quantum dot white light-emitting diode
}

\author{
Xuyong Yang, ${ }^{1}$ Yoga Divayana, ${ }^{1}$ Dewei Zhao, ${ }^{1}$ Kheng Swee Leck, ${ }^{1}$ Fen Lu, ${ }^{2}$ \\ Swee Tiam Tan, ${ }^{1}$ Agus Putu Abiyasa, ${ }^{1}$ Yongbiao Zhao, ${ }^{1}$ Hilmi Volkan Demir, ${ }^{1,2,3, a)}$ \\ and Xiao Wei Sun ${ }^{1, a)}$ \\ ${ }^{1}$ Luminous! Center of Excellence for Semiconductor Lighting and Displays, School of Electrical and \\ Electronic Engineering, Nanyang Technological University, Nanyang Avenue, Singapore 639798 \\ ${ }^{2}$ School of Physical and Mathematical Sciences, Nanyang Technological University, Nanyang Avenue, \\ Singapore 639798 \\ ${ }^{3}$ Department of Electrical and Electronics Engineering, Department of Physics, UNAM-Institute of Materials \\ Science and Nanotechnology, Bilkent University, Bilkent, Ankara 06800, Turkey
}

(Received 23 October 2012; accepted 14 November 2012; published online 6 December 2012)

\begin{abstract}
We report a bright cadmium-free, InP-based quantum dot light-emitting diode (QD-LED) with efficient green emission. A maximum brightness close to $700 \mathrm{~cd} / \mathrm{m}^{2}$ together with a relatively low turn-on voltage of $4.5 \mathrm{~V}$ has been achieved. With the design of a loosely packed QD layer resulting in the direct contact of poly[ $N, N^{\prime}$-bis(4-butylphenyl)- $N, N^{\prime}$-bis(phenyl)benzidine] (poly-TPD) and $2,2^{\prime}, 2^{\prime \prime}-(1,3,5$-benzinetriyl)-tris(1-phenyl-1- $H$-benzimidazole) (TPBi) in the device, a ternary complementary white QD-LED consisting of blue component (poly-TPD), green component (QDs), and red component (exciplex formed at the interface between poly-TPD and TPBi) has been demonstrated. The resulting white QD-LED shows an excellent color rendering index of 95 . (C) 2012 American Institute of Physics. [http://dx.doi.org/10.1063/1.4769347]
\end{abstract}

Colloidal quantum dot light-emitting devices (QD-LEDs) have generated considerable interest for applications such as flat panel displays with improved color saturation and lighting sources with high color rendering index (CRI) ${ }^{1-9}$ The electroluminescence $(\mathrm{EL})$ spectrum of OD-LEDs is generally narrow and can be conveniently changed from blue to red by tuning the size of quantum dots. To date, the performance of QDLEDs is good enough to be compared with organic lightemitting diode (OLEDs) and GaN-based LEDs. However, the serious drawback of the present colloidal QD-LED technology is that it is heavily dependent on cadmium-based quantum dots, which has severely hindered the commercialization of the QD-LED technology. ${ }^{10,11}$ Indium phosphide is considered as the ideal alternative, which offers a similar emission spectrum but without intrinsic toxicity. ${ }^{12-18}$ Previous studies have demonstrated that InP-based quantum dots can be well used in QDLEDs. ${ }^{19-21}$ However, the overall performance for InP-based QD-LEDs has been low. On the other hand, the QD-LEDs with efficient white emission have rarely been reported. At present, it is almost impossible to obtain high-performance white QDLEDs only by mixing blue-, green-, and red-emitting QDs as white emissive layer due to the low efficiency for the blue QDs. ${ }^{2,7}$ Currently, some research groups demonstrated that the combination of emission of organic molecules and QDs is quite promising for fabricating high-performance white hybrid QDLEDs. ${ }^{1,22,23}$ Nevertheless, much work is further needed in hybrid QD-LED research for improved performance.

Here, we report green InP-based QD-LEDs with a maximum brightness close to $700 \mathrm{~cd} / \mathrm{m}^{2}$, accompanied with a relatively low turn-on voltage of $4.5 \mathrm{~V}$, which is the best performance ever reported for InP-based QD LEDs. Mean-

\footnotetext{
${ }^{\text {a) }}$ Authors to whom correspondence should be addressed. Electronic addresses: hvdemir@ntu.edu.sg and EXWSun@ntu.edu.sg.
}

while, with the fabrication of a loosely packed QD layer to form some direct contact between the hole-transporting layer poly [ $N, N^{\prime}$-bis(4-butylphenyl)- $N, N^{\prime}$-bis(phenyl)benzidine] (poly-TPD) and electron-blocking layer $2,2^{\prime}, 2^{\prime \prime}$-(1,3,5-benzinetriyl)-tris(1-phenyl-1- $H$-benzimidazole) (TPBi), we demonstrated a ternary complementary white QD-LED with the blue emission from poly-TPD, green emission from QDs, and the red exciplex emission between poly-TPD and TPBi. The resulting ternary complementary white QD-LEDs show good photometric performance with a high CRI of 95 and a moderate low correlated color temperature (CCT) of $4710 \mathrm{~K}$.

For the present work, the InP-ZnSeS core-shell structured QDs used here were prepared by a modified literature procedure. ${ }^{21}$ A typical procedure is given as follows: $1 \mathrm{ml}$ of indium oleate $\left(\operatorname{In}(\mathrm{OA})_{3}\right)$ solution, $0.25 \mathrm{ml}$ of zinc oleate $\left(\mathrm{Zn}(\mathrm{OA})_{2}\right)$ solution, and $7.5 \mathrm{ml}$ of octadecene (ODE) were loaded into 3-necked round flask and degassed. Subsequently, $0.1 \mathrm{mmol}$ of tris(trimethylsilyl)phosphine $\left((\mathrm{TMS})_{3} \mathrm{P}\right)$ in $1 \mathrm{ml}$ of ODE was injected at an elevated temperature $\left(\sim 150^{\circ} \mathrm{C}\right)$ under $\mathrm{Ar}$ atmosphere. Next, the mixture was quickly heated up to $300^{\circ} \mathrm{C}$ with strong agitation for $10 \mathrm{~min}$. After that, $5 \mathrm{ml}$ of $\mathrm{Zn}(\mathrm{OA})_{2}$ solution, and $0.1 \mathrm{mmol}$ of selenium (Se) and $1.9 \mathrm{mmol}$ of sulphur ( $\mathrm{S}$ ) dissolved in $2 \mathrm{ml}$ of trioctylphosphine (TOP) were sequentially added into the reaction system which was cooled down to $220^{\circ} \mathrm{C}$ beforehand, and then were repeatedly heated up to $300^{\circ} \mathrm{C}$. Finally, the cadmium-free QDs consisting of InP cores coated with $\mathrm{ZnSeS}$ composition gradient shells were obtained and these QDs exhibited a narrow size distribution with an average diameter of $\sim 4 \mathrm{~nm}$. Using the resulting green-emitting InP-based QDs, we succeeded in fabricating the QD-LED devices with a multilayer structure of ITO/poly(3,4-ethylenedioxythiophene)poly(styrenesulfonate) (PEDOT:PSS)/poly-TPD/QDs/TPBi/LiF/Al. The LED output spectrum was recorded at the bias voltage of $6.5 \mathrm{~V}$. Figure 1(a) 

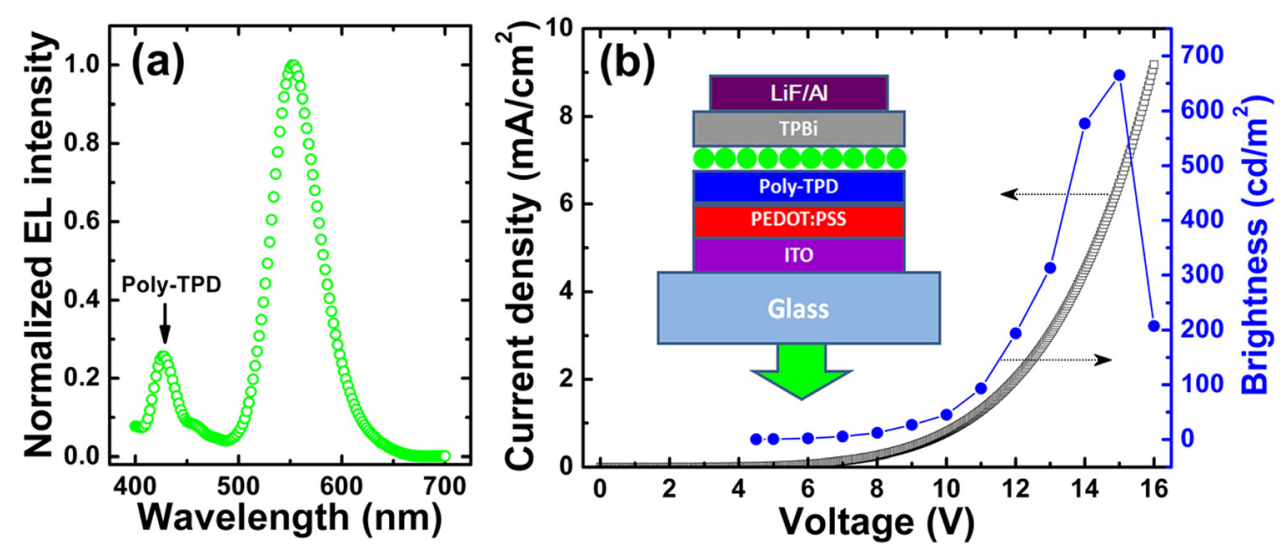

FIG. 1. (a) EL spectrum and (b) currentvoltage and brightness-voltage properties of QD-LEDs. Inset: the structure of the InP-based QD-LEDs. shows a clear green emission peaking at $550 \mathrm{~nm}$ with a full width at half maximum (FWHM) of $55 \mathrm{~nm}$. The weak emission in the blue-wavelength region is from poly-TPD. The emission from poly-TPD can be changed by controlling the hole-transporting layer (poly-TPD) and electron-transporting layer (TPBi) thicknesses in the device. Figure 1(b) presents the output performance of the optimized QD-LEDs. Its maximum brightness is close to $700 \mathrm{~cd} / \mathrm{m}^{2}$ and the external quantum efficiency (EQE) is $0.26 \%$, which are significantly improved compared to the previously reported values (i.e., the maximum brightness and EQE were around $16 \mathrm{~cd} / \mathrm{m}^{2}$ and $0.008 \%$, respectively). ${ }^{21}$ The inset of Figure 1(b) shows the structure of these QD-LEDs tested.

A QD-free LED processing with the structure of ITO/ PEDOT:PSS/poly-TPD/TPBi/LiF/Al was also fabricated for comparison. Interestingly, we observed that, besides the blue poly-TPD emission, a strong red emission peaking at $\sim 620 \mathrm{~nm}$ appeared (Figure 2(a)). This red emission is attributed to an exciplex formed at the interface between polyTPD and TPBi. Such exciplex is a kind of excited state complex formed between the donor and the acceptor, which are in the excited state and the other in the ground state, respectively. A similar exciplex emission formed between hole-transporting layer and polyfluorenes is previously reported by Li et al. ${ }^{24}$ From the energy levels of poly-TPD and TPBi shown in Figure 2(b), it can be found that the energy gap between the HOMO of poly-TPD $(\sim 5.2 \mathrm{eV})$ and the LUMO of TPBi $(-3.2 \mathrm{eV})$ is $\sim 2.0 \mathrm{eV}$, which is perfectly matching the red emission band. In our case, the exciplex emission shows a strong voltage-dependence. At low bias $(5 \mathrm{~V})$, the EL spectrum is clearly dominated by emission from the poly-TPD due to most of the excitons are formed inside the bulk of the poly-TPD and there is no exciplex emission observed. As the applied voltage is increased, the recombination region of excitons shifts toward the interface of polyTPD and TPBi, where the exciplex emission occurred and its relative contribution enhances compared with the blue emission of ploy-TPD. Such red emission from charge-transfer (CT) exciplexes formed at the interface between poly-TPD and TPBi can be utilized for white QD-LEDs.

To combine the green (QDs), blue (poly-TPD), red (exciplex) emission for a white LED, we fabricated the QDLED with loosely packed QD film where there are some space between the adjacent QDs to facilitate a direct contact of poly-TPD and TPBi (Figure 3(a)). The loosely packed QD layer was obtained by reducing the concentration of QDs and increasing the speed rate of spin-coating. Figure 3(b) shows the atomic force microscope (AFM) images of loosely packed QD layer deposited onto a $40 \mathrm{~nm}$ thick poly-TPD layer annealed at $110^{\circ} \mathrm{C}$, and voids between QDs can be clearly observed in the corresponding inset. The LED output spectrum recorded at the bias voltage of $15 \mathrm{~V}$ exhibits a broadband coverage over the entire visible wavelength range, and main emission peaks can be observed in the spectrum (Figure 3(c)). The green emission of QDs is spectrally complementary to the blue emission from poly-TPD and the red emission from the exciplex of poly-TPD and TPBi for white light generation. The CIE coordinates of the InP-based QD-LED is $(0.349,0.342)$, which is close to the balanced white coordinates (Figure 3(d)). In addition, the white light of the QD-LED is characterized with a high CRI of 95 and a moderate CCT of $4710 \mathrm{~K}$. The CRI is significantly higher than that of most of solid-state white LEDs. An image of the white QD-LED output was recorded at a luminance of $322 \mathrm{~cd} / \mathrm{m}^{2}$ (inset of Figure 3(d)), which displays bright and uniform white emission.

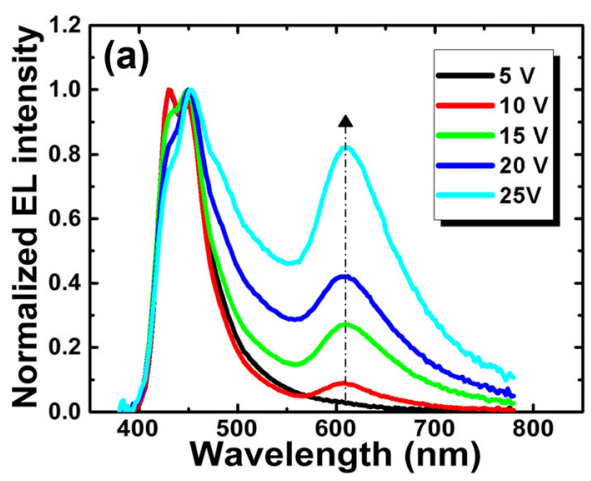

(b)

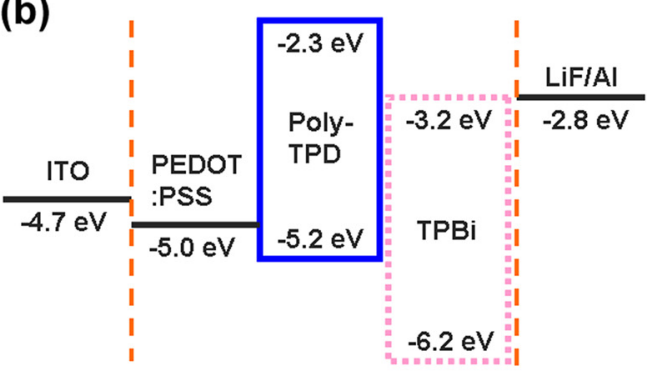

FIG. 2. (a) EL spectra of the device without QDs for different applied bias. (b) Energy band diagram of the devices without QDs. The theoretical values for the valence (or HOMO) and conduction bands (or LUMO) for individual layers were obtained from Ref. 25. 

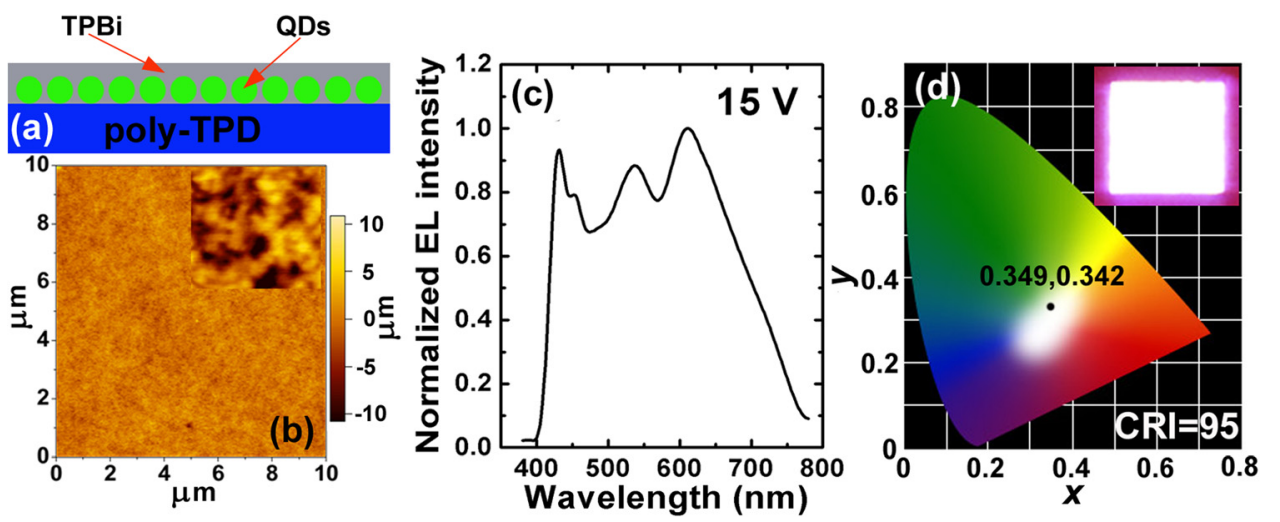

FIG. 3. (a) Schematic illustration of ternary complementary QD-LED (not drawn to scale). A loosely packed layer of quantum dots located at the interface between poly-TPD and TPBi with QDs embedded into electron transporting (TPBi) films. (b) AFM topography (height) image of a loosely-packed QD film spin-coated on top of poly-TPD. (c) EL spectrum of ternary complementary QD-LEDs. (d) CIE chromaticity coordinate diagram of the white QD-LEDs, along with a photograph of a QD-LED with a pixel size of $3 \mathrm{~mm}$ $\times 3 \mathrm{~mm}$ (inset).
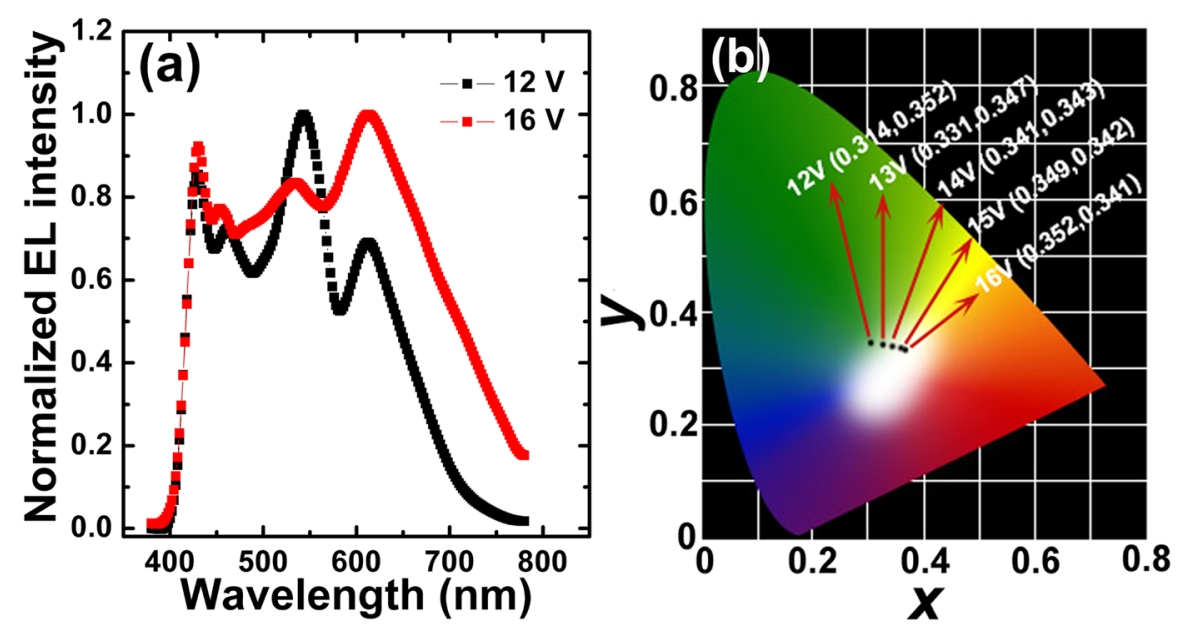

FIG. 4. (a) EL spectra of QD-LEDs under low voltage $(12 \mathrm{~V})$ and high voltage $(16 \mathrm{~V})$, and $(\mathrm{b})$ CIE chromaticity coordinate diagram for the QDLEDs at different biases.

The spectral power distribution of the ternary complementary QD-LEDs presented herein also exhibits a distinctive voltage dependence. Figure 4(a) shows the EL spectrum color shift in the QD-LED at the low applied bias $(12 \mathrm{~V})$ and high applied bias $(16 \mathrm{~V})$. With increasing bias, we observe a rapid increase of the red spectral component in the EL spectrum relative to the initially dominant blue and green spectral components. This evolution of spectral features with the increasing bias is consistent with that of the devices without QDs (Figure 2(a)). It can be seen that the blue spectral component from poly-TPD enhances relatively faster with the increasing bias compared with the green emission from QDs. This indicates that more excitons are harvested in poly-TPD possibly due to the reduced exciton confinement effect ${ }^{26,27}$ of polyTPD on the QD layer as the driving voltage increases. The color coordinates for the QD-LEDs under different bias conditions $(12-16 \mathrm{~V})$ have been calculated in the present study and presented in the CIE 1931 color diagram in Figure 4(b). The chromaticity calculation suggests that it is possible to tune the desired color coordinates of the three emissive complements in the QD-LED by adjusting the bias voltage.

In summary, the InP-based QD-LEDs with efficient green emission have been fabricated in the work. Additionally, with the design of a loosely packed QD layer resulting in the direct contact of poly-TPD and TPBi, a ternary complementary white QD-LED consisting of blue component (polyTPD), green component (QDs), and red component (exciplex formed at the interface between poly-TPD and TPBi) has been demonstrated with a high color rendering index of 95 . Realistic progress towards the practical application in white
QD-LEDs using InP-based QDs has been achieved. Furthermore, the sucesssful realization of the ternary complementary white QD-LEDs may provide a promising strategy for design and fabrication of high-peformance optoelectronic devices with multi-color components.

The authors would like to thank for the financial support from Singapore National Research Foundation under the programs of NRF-RF-2009-09 and NRF-CRP-2011-02 and the Science and Engineering Research Council, Agency for Science, Technology and Research (A*STAR) of Singapore (Project No. 092101 0057). The work was also supported by the National Natural Science Foundation of China (NSFC) (Project Nos. 61006037, 61177014, and 61076015), and Tianjin Natural Science foundation (Project Nos. 11JCZDJC21900 and 11JCYDJC25800).

${ }^{1}$ X. Yang, D. Zhao, K. S. Leck, S. T. Tan, Y. X. Tang, J. Zhao, H. V. Demir, and X. W. Sun, Adv. Mater. 24, 4180 (2012).

${ }^{2}$ L. Qian, Y. Zheng, J. Xue, and P. H. Holloway, Nature Photon. 5, 543 (2011). ${ }^{3}$ K. S. Cho, E. K. Lee, W. J. Joo, E. Jang, T. H. Kim, S. J. Lee, S. J. Kwon, J. Y. Han, B. K. Kim, B. L. Choi, and J. M. Kim, Nature Photon. 3, 341 (2009).

${ }^{4}$ J. M. Caruge, J. E. Halpert, V. Wood, V. Bulović, and M. G. Bawendi, Nature Photon. 2, 247 (2008).

${ }^{5}$ Z. Tan, Y. Zhang, C. Xie, H. Su, J. Liu, C. Zhang, N. Dellas, S. E. Mohney, Y. Wang, J. Wang, and J. Xu, Adv. Mater. 23, 3553 (2011).

${ }^{6}$ E. M. Likovich, R. Jaramillo, K. J. Russell, S. Ramanathan, and V. Narayanamurti, Adv. Mater. 23, 4521 (2011).

${ }^{7}$ J. Kwak, W. K. Bae, D. Lee, I. Park, J. Lim, M. Park, H. Cho, H. Woo, D. Y. Yoon, K. Char, S. Lee, and C. Lee, Nano Lett. 12, 2362 (2012).

${ }^{8}$ D. P. Puzzo, E. J. Henderson, M. G. Helander, Z. Wang, G. A. Ozin, and Z. Lu, Nano Lett. 11, 1585 (2011). 
${ }^{9}$ J. W. Stouwdam and R. A. J. Janssen, Adv. Mater. 21, 2916 (2009).

${ }^{10}$ T. Erdem and H. V. Demir, Nature Photon. 5, 126 (2011).

${ }^{11}$ D. V. Talapin, J. S. Lee, M. V. Kovalenko, and E. V. Shevchenko, Chem. Rev. 110, 389 (2010)

${ }^{12}$ P. M. Allen, B. J. Walker, and M. G. Bawendi, Angew. Chem. 122, 772 (2010),

${ }^{13}$ S. Kim, J. Park, T. Kim, E. Jang, S. Jun, H. Jang, B. Kim, and S. W. Kim, Small 7, 70 (2011).

${ }^{14}$ H. Chibli, L. Carlini, S. Park, N. M. Dimitrijevic, and J. L. Nadeau, Nanoscale 3, 2552 (2011).

${ }^{15}$ D. D. Lovingood and G. F. Strouse, Nano Lett. 8, 3394 (2008).

${ }^{16}$ R. Xie and X. Peng, J. Am. Chem. Soc. 131, 10645 (2009).

${ }^{17}$ S. Tamang, G. Beaune, I. Texier, and P. Reiss, ACS Nano 5, 9392 (2011).

${ }^{18}$ K. Huang, R. Demadrille, M. G. Silly, F. Sirotti, P. Reiss, and O. Renault, ACS Nano 4, 4799 (2010).

${ }^{19}$ E. Mutlugün, P. L. Hernandez-Martinez, C. Eroğlu, Y. Coşkun, T. Erdem, V. K Sharma, E. Ünal, S. K. Panda, S. G. Hickey, N. Gaponik, A. Eychmuller, and H. V. Demir, Nano Lett. 12, 3986 (2012).
${ }^{20}$ J. Ziegler, S. Xu, E. Kucur, F. Meister, M. Batentschuk, F. Gindele, and T. Nann, Adv. Mater. 20, 4068 (2008).

${ }^{21}$ J. Lim, W. K. Bae, D. Lee, M. K. Nam, J. Jung, C. Lee, K. Char, and S. Lee, Chem. Mater. 23, 4459 (2011).

${ }^{22}$ Y. Zhang, C. Xie, H. Su, J. Liu, S. Pickering, Y. Wang, W. W. Yu, J. Wang, Y. Wang, J. I. Hahm, N. Dellas, S. E. Mohney, and J. Xu, Nano Lett. 11, 329 (2011).

${ }^{23}$ M. A. Schreuder, K. Xiao, I. N. Ivanov, S. M. Weiss, and S. J. Rosenthal, Nano Lett. 10, 573 (2010).

${ }^{24}$ Q. J. Sun, B. H. Fan, Z. A. Tan, C. H. Yang, and Y. F. Li, Appl. Phys. Lett. 88, 163510 (2006).

${ }^{25}$ Q. Sun, G. Subramanyam, L. Dai, M. Check, A. Campbell, R. Naik, J. Grote, and Y. Wang, ACS Nano 3, 737 (2009).

${ }^{26}$ Y. Zheng, S.-H. Eom, N. Chopra, J. Lee, F. So, and J. Xue, Appl. Phys. Lett. 92, 223301 (2008).

${ }^{27}$ K. Goushi, R. Kwong, J. J. Brown, H. Sasabe, and C. Adachi, J. Appl. Phys. 95, 7798 (2004). 